(4) Distance between the flange and the two focal surfaces for objects at infinity not located on the optical axis but subtending, with the latter, various angles with the iris closed. The difference between these two distances represents the amounts of pure astigmatism with which the lens is afflicted at that particular field angle; while the difference between each of these two measurements and the flange focal length as measured according to (1) represents the tangential and sagittal field curvature.

(5) Same as (4), but for different iris settings to determine the additional influence of coma and oblique spherical aberration.

It should be noted here again that the measurements (2) and (5) do not represent the mathematical image point for that particular aperture but rather the circle of least confusion, taking into consideration the sum total of all aberrations which come into play at the image formation for that particular point of the field.
The variations of these distances give a reliable measure for the evaluation of the lens performance under actual working conditions.

16. Figure 2 shows the instrument mounted on a standard optical bench.

It is obvious that, from the standpoint of production engineering, the necessary computations have been reduced to an absolute minimum. Nearly all data required to plot graphs of the resolution of the lens at different apertures and field angles can be directly read off from the instrument.

The instrument is also very sturdy and needs no adjustment once it is set. Like the "microfocuser," it can be operated by an unskilled worker after very short instruction.

An instrument of this type has been in practical daily use for over a year and has given most satisfactory results.

\title{
Improvements in Mass Spectrometers for the Measurement of Small Differences in Isotope Abundance Ratios
}

\author{
C. R. McKinney, J. M. McCrea, S. Epstein, H. A. Allen, and H. C. Urey \\ Institute for Nuclear Studies, University of Chicago, Chicago, Illinois
}

(Received March 30, 1950)

\begin{abstract}
A Nier-type mass spectrometer and its associated electronic units have been constructed for the purpose of measuring small variations in the abundances of oxygen of mass 18 and of carbon of mass 13 in carbon dioxide, and of oxygen of mass 18 in oxygen gas, to an accuracy of \pm 0.01 percent of the abundance of these isotopes.

The electronic units of the necessary stability for this degree of accuracy are described. A gas feed system is described which permits fast alternate introduction of the sample of gas to be analyzed and a standard gas into the mass spectrometer. All measurements of the variation in the abundance of the oxygen and carbon isotopes are made with reference to a standard.
\end{abstract}

$\mathrm{D}$ URING recent years great progress has been made in developing mass spectrometers for the measurement of the relative abundance of isotopes. Particularly sensitive instruments have been developed by Nier, Thode, and others. ${ }^{1}$ Basically, the mass spectrometer and electronic units in our research were those described by Nier. We report only the changes we made in these that assisted us in being able to measure small differences in the abundance of the rarer isotopes in gaseous compounds. The method has been applied to carbon and oxygen in carbon dioxide and to oxygen in oxygen gas. Our success in securing this greater sensitivity depends both upon increasing the intensity of the ion beam and upon increasing the absolute sensitivity of detection. In doing this, it has been necessary to improve the stability

${ }^{1}$ A. O. Nier, Rev. Sci. Inst. 18, 398 (1947). Thode, Graham, Ziegler, Can. J. Research B23, 40 (1945). For an excellent review of this subject, see M. G. Inghram, Advances in Electronics 1, 219 (1948). of the beam intensity and output from the amplifiers by the use of more stable power supplies, more reliable amplification systems, and an improved emission regulator. Also, it has been necessary to use a method for rapid change of samples in order to decrease errors due to general variability of the instrument with time, and it has proved essential that a recording potentiometer be used to detect and record the state of balance of the simultaneously collected ion beams. The instrument has been constructed with the objective of measuring small differences in isotopic abundances of the oxygen isotopes as a means of measuring paleotemperatures, but the instrument and our procedures may be useful in other researches.

\section{POWER SUPPLY FOR ELECTROMAGNET}

Figure 1 shows the circuit diagram of the power supply used to furnish the current for the magnet windings 


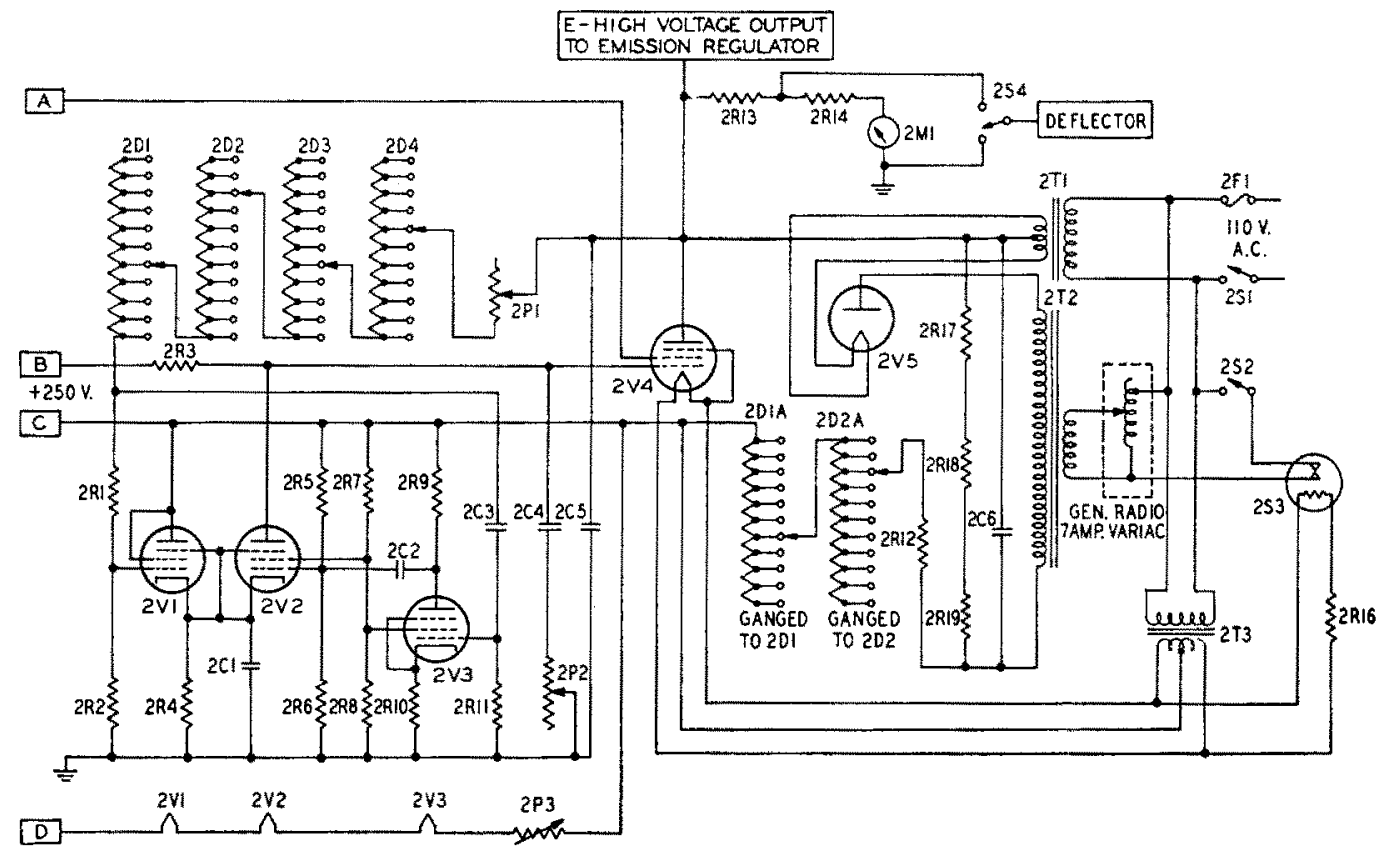

Fig. 2, Parts list for high voltage supply.

\begin{tabular}{|c|c|}
\hline $\begin{array}{l}2 \mathrm{R} 1 \\
2 \mathrm{R} 2,2 \mathrm{R} 6,2 \mathrm{R} 8 \\
2 \mathrm{R} 3 \\
2 \mathrm{R} 4 \\
2 \mathrm{R} 5 \\
2 \mathrm{R} 7 \\
2 \mathrm{R} 9 \\
2 \mathrm{R} 10 \\
2 \mathrm{R} 11 \\
2 \mathrm{R} 12 \\
2 \mathrm{R} 13,2 \mathrm{R} 14 \\
2 \mathrm{R} 16 \\
2 \mathrm{R} 17,2 \mathrm{R} 18,2 \mathrm{R} 19 \\
2 \mathrm{D} 1 \mathrm{~A} \\
2 \mathrm{D} 2 \mathrm{~A} \\
2 \mathrm{D} 1 \\
2 \mathrm{D} 2 \\
2 \mathrm{D} 3 \\
2 \mathrm{D} 4 \\
2 \mathrm{P} 1 \\
2 \mathrm{P} 2 \\
2 \mathrm{P} 3\end{array}$ & $\begin{array}{l}250,000 \text { ohms, precision wire wound } \\
75,000 \text { ohms, precision wire wound } \\
1 \text { thegohm, precision wire wound } \\
25,000 \text { ohms, precision wire wound } \\
50,000 \text { ohms, precision wire wound } \\
35,000 \text { ohms, precision wire wound } \\
30,000 \text { ohms, precision wire wound } \\
40,000 \text { ohms, precision wire wound } \\
2,2 \text { megohms carbon } 1 \text { watt } \\
50,000 \text { ohms, } 100 \text { watt } \\
2 \text { megohms, precision wire wound } \\
\text { Reduces } 10 \text { v to } 6 \text { v required by } 253 \text { relay } \\
10 \text { megohms, } 2 \text { watt } \\
10 \text { steps, } 5000 \text { ohms per step (10 watt each) } \\
10 \text { steps, } 470 \text { ohms per step ( } 2 \text { watt each) } \\
10 \text { steps, } 100,000 \text { ohms per step precision wire wound } \\
10 \text { steps, } 10,000 \text { ohms per step precision wire wound } \\
\text { General Radio decade type } 510 \text { E } 1000 \text { ohms per step } \\
\text { General Radio decade type } 510 D \text { D } 100 \text { ohms per step } \\
100 \text { ohms, wire wound potentiometer } \\
3 \text { megohms, carbon potentiometer } \\
1300 \text { ohms, } 50 \text { watt potentiometer }\end{array}$ \\
\hline
\end{tabular}

automatic magnetic scanning for the desired mass range.

\section{HIGH VOLTAGE SUPPLY}

The high voltage supply shown in Fig. 2 furnishes a continuously variable regulated voltage in the range 600 to 2200 volts for accelerating the ions in the mass spectrometer. The voltage of the output is varied by means of decades 2D1 to $2 \mathrm{D} 4$, which are ganged with 2D1A and 2D2A to keep the load across the rectifier and transformer nearly constant. Condenser $2 \mathrm{C} 4$ and resistor $2 \mathrm{P} 2$ are included to eliminate tendencies for oscillation. Tube $2 \mathrm{~V} 3$ performs the function of applying part of the output ripple in a degenerative manner to the grid of $2 \mathrm{~V} 2$ which in turn acts to reduce the ripple of the output. A 1 percent variation in the line voltage appears as a 0.001 percent variation of output at 600 volts and as 0.005 percent at 2200 volts, with internal resistances of 1 and 4 ohms respectively at these outputs.

The reference voltage of 250 volts, the heater current for control tubes $2 \mathrm{~V} 1,2 \mathrm{~V} 2$, and $2 \mathrm{~V} 3$, and the other

\begin{tabular}{|c|c|}
\hline $2 \mathrm{~V}_{1}, 2 \mathrm{~V}_{2}, 2 \mathrm{V3}$ & $12 A Y 6$ \\
\hline $2 \sqrt{2}+2 \sqrt{2}, 283$ & 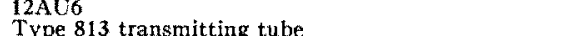 \\
\hline $2 V 5$ & $\begin{array}{l}\text { Type } 813 \text { transmitting tube } \\
\text { Type } 8020 \text { high voltage rectifier }\end{array}$ \\
\hline $2 \mathrm{Cl}$ & 0.01 thifd $600 \mathrm{y}$ \\
\hline $2 \mathrm{C} 2$ & $0,25 \mathrm{mfd} 400 \mathrm{v}$ \\
\hline $2 \mathrm{C} 3$ & $2 \operatorname{mfd} 600 \mathrm{v}$ \\
\hline & $0.1 \mathrm{mfd} 600 \mathrm{v}$ \\
\hline $2 \mathrm{CS}$ & $4 \mathrm{mfd} 3000 \mathrm{v}$ \\
\hline $2 \mathrm{C} 6$ & $4 \mathrm{mfd} 4000 \mathrm{v}$ \\
\hline $2 \mathrm{TI}$ & $\begin{array}{l}\text { Stancor filament transformer type } \mathrm{P}-4086,5 \mathrm{v} \text { c.t. } \\
14 \text { amp. } 10.000 \mathrm{v} \text { insulation }\end{array}$ \\
\hline $2 \mathrm{~T} 2$ & $\begin{array}{l}\text { Maloney Electric Company high voltage transformer } \\
\text { part No. } 5503 \text { (Army surplus) } 5600 \text { v at } 0.1 \text { amp. } \\
\text { (reduced to } 3700 \mathrm{v} \text { with } 1 \text { kva Variac) }\end{array}$ \\
\hline $2 \mathrm{~T} 3$ & $\begin{array}{l}\text { Stancor filament transformer type } 613910 \text { v c.t. } 8 \text { amp. } \\
\text { General Radio variac } 7 \text { a amp. capacity }\end{array}$ \\
\hline $2 \mathrm{Mi}$ & 0-1 milliamp. meter \\
\hline & S.P.S.T. toggle switch \\
\hline 2 & S.P.S.T. toggle switch -high voltage on-off \\
\hline & Amperite thermostatic delay relay type 6 N045 \\
\hline & S.P.S.T. high voltage rotary switch for beam on \\
\hline
\end{tabular}

necessary voltages are obtained from the appropriate places in the magnet power supply $(C, D, A$, and $B)$. The thermal time delay relay $2 \mathrm{~S} 3$ protects the cathodes of $2 \mathrm{~V} 4$ and $2 \mathrm{~V} 5$.

\section{THE ELECTRON EMISSION REGULATOR}

The emission regulator circuit as shown in Fig. 3 consists of two parts. One part is a power supply similar to the one used in the magnet circuit. Since the requirements for this power supply are less critical than the one used for furnishing current to the magnet windings, the plate supply voltage for the amplifier tube (3V12) is obtained from the unregulated direct current from the rectifiers. This power supply provides the electron accelerating voltage and the trap voltage in the ion source.

Regulation of electron emission of the filament in the source is accomplished by the second part of the emission regulator. Electron emission currents from the filament in the ion source flows through resistors $3 \mathrm{R} 10$ and $3 \mathrm{P} 2$ and the resulting voltage drop is amplified and applied to the grid of a series control tube (3V14) which 


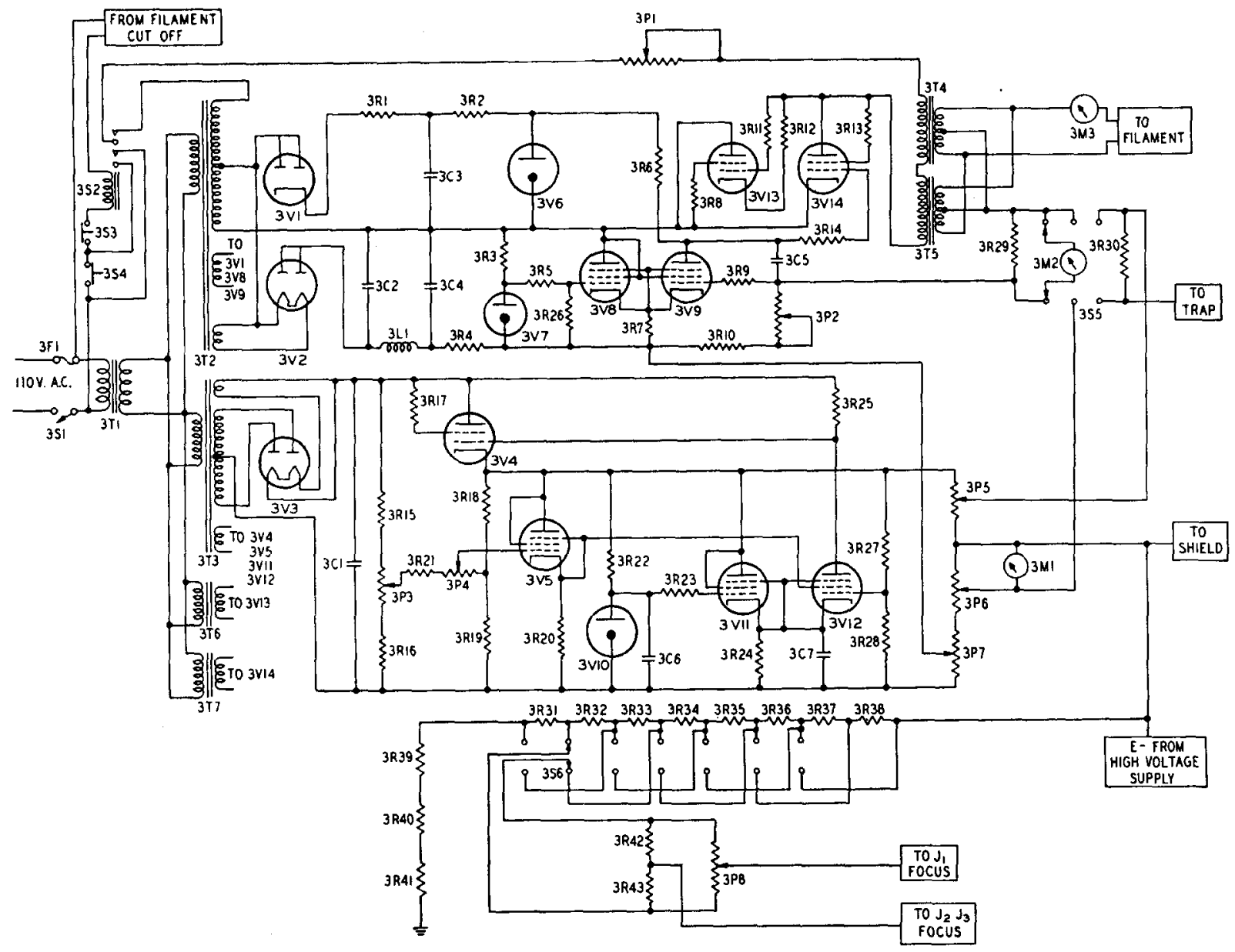

FIG. 3. Parts list for emission regulator.

3R1
3R2
3R3
3R4
3R5
3R6
3R7
3R8, 3R13
3R9, 3R11, 3R14
3R10
3R12 2 R $19,3 R 20,3 R 22$
3R15, 3R19, 3R2
3R16
3R17
3R18
3R25
3R26
3R27
3R24, 3R28
3R29

3R30
3R21, 3R23, 3R31 to 3R38
3R39, 3R40, 3R41
3R42, 3R43
3P1
3P2
3P3

3P4
3P5
3P6
3P7
3P8
3T1

3T2
3T3
3T4, 3T5
3T6, 3T7
3C1, 3C3
3C2, 3C4
3C5
3C6, 3C7
3M1
3M2
3M3
3V1
3V2, 3V3
3V4
3V5, 3V8, 3V9, 3V12
3V6, 3V7
3V10
3V11
3V13, 3V14
3S1
3S2
3S3
3S4
3S5
3S6

0.5 megohm, carbon potentiometer

5000 ohms, wire wound

10,000 ohms, wire wound

$5000 \mathrm{ohms}$, wire wound

3 tnegohm, carbon potentiomete

hordarson No. T18V01 $1: 1$ isolation trans

former (changes made so secondary is insulated for $3500 \mathrm{v}) 250$ volt-ampere capacity Acme No. T4822 power transformer

Stancor No. P6143 power transformer

6.3 volt, 5 amperes filament transformers

6.3 volt, 2 amperes filament transformers

$16 \mathrm{mfd} 600 \mathrm{v}$

$8 \mathrm{mfd} 600 \mathrm{v}$

$0.05 \mathrm{mfd} 600$

$0.01 \mathrm{mfd} 400 \mathrm{v}$. voltmete

$0-100$ microampere d.c. -1000 ohms resistance

$0-10$ microampere

$6 \times 4$

$5 \times 4$

$5 \mathrm{Y3}$

6 AU6

OA2 miniature voltage regulator tube 5651 miniature voltage regulator tube $6 \mathrm{AG}$

S.P.S.T. toggle on-off switch

D.P.D.T. high voltage relay

Push switch normally closed

Push switch normally open

2 pole three position switch controls the current flowing through the primary of transformers 3T4 and 3T5. The secondaries of these transformers supply the current to the filament in the mass spectrometer. Tube 3V13 serves to maintain proper wave form of the primary current. The controlled range of electron emission from the filament in the mass spectrometer extends from 100 to 500 microamperes depending upon the setting of $3 \mathrm{P} 2$. A 1 percent change in line voltage input results in a 0.02 percent change in average emission. Switch $3 \mathrm{~S} 5$ is a three-position switch 


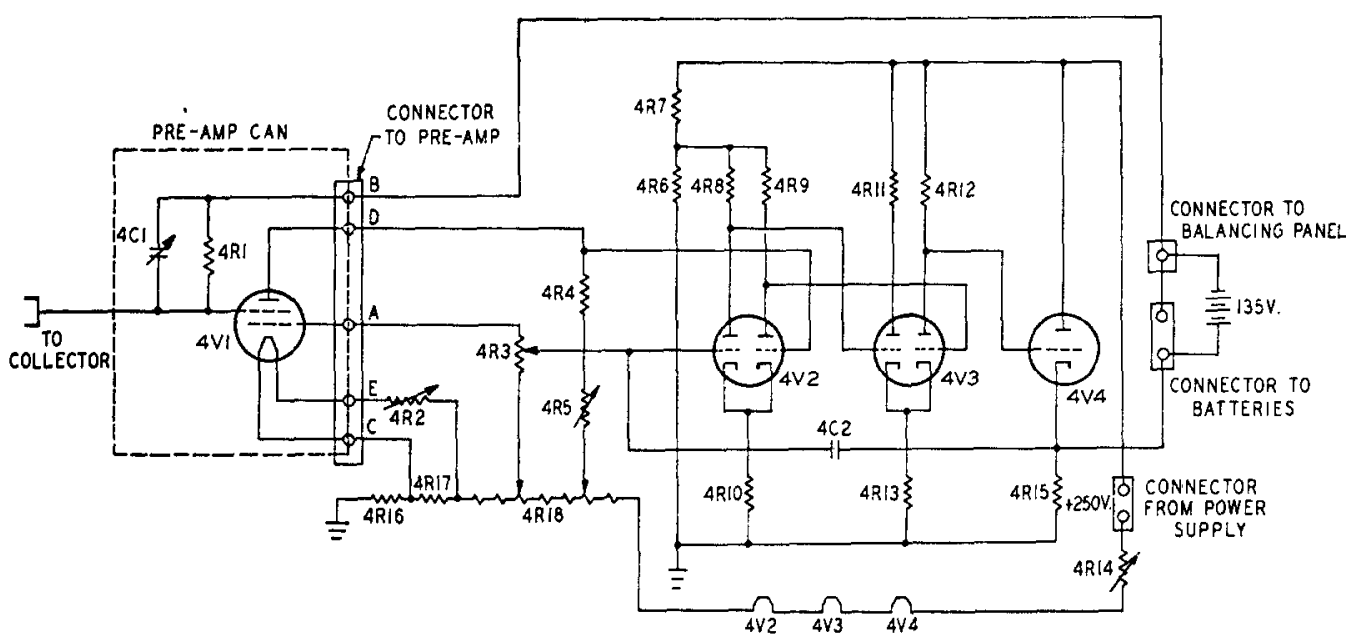

FIG. 4. Parts list for d.c. amplifier.

$\begin{array}{ll}\text { 4R1 } & \begin{array}{l}1.5 \times 10^{10} \text { ohm Victoreen Hi-Megohm obtained from } \\ \text { Victoreen Instrument Company, Cleveland, Ohio } \\ \text { 4R2 }\end{array} \\ \text { 4R3 } & \text { ohm wire wound potentiometer } \\ \text { 4R4 } & \text { Corporation, South Pasaden, California } \\ \text { 4R5 } & 250,000 \text { ohms, precision wire wound } \\ \text { 4R6 } & 100,000 \text { ohms Helipot 15 turns } \\ \text { 4R7 } & 20,000 \text { ohms, precision wire wound } \\ \text { 4R8, 4R9 } & 35,000 \text { ohms, precision wire wound } \\ \text { 4R10 } & 500,000 \text { ohms, precision wire wound } \\ \text { 4R11, 4R12 } & 75,000 \text { ohms, precision wire wound } \\ \text { 4R13 } & \text { 1 megohm, precision wire wound } \\ & 300,000 \text { ohms, precision wire wound }\end{array}$

which allows meter $3 \mathrm{M} 2$ to read either trap current, total emission current or to indicate the zero adjustment of $3 \mathrm{P} 6$ so that meter $3 \mathrm{M} 1$ reads electron accelerating voltage.

\section{ION CURRENT AMPLIFICATION}

Essentially the same amplifier design as described by Nier was used initially in this research. A stable d.c. amplifier is obtained by using our previously described power supply and by using the tubes described in Fig. 4 . To allow collection of currents of approximately 3.7 $\times 10^{-9}$ and $1.5 \times 10^{-11}$ ampere for masses 44 and 46 respectively, and to get sensitivity of 0.2 permil in determining the ratio of mass 46 to mass 44 , the respective sizes of the resistors $4 \mathrm{R} 1$ of the two amplifiers must be approximately $1.5 \times 10^{10}$ and $1.5 \times 10^{11} \mathrm{ohms}$.

Since the inherent difficulties present in sensitive d.c. amplifiers did not permit day to day use of the mass spectrometers for analyses with the accuracy required in this research, a different amplification system was tried. A vibrating reed electrometer with its associated amplifier in conjunction with a null system described by Nier, Ney, and Inghram, ${ }^{3}$ where the vibrating reed replaces the FP54 electrometer, gave continuously satisfactory performance.

A schematic diagram of this system is given in Fig. 5.

\section{GAS FEED AND RECORDING POTENTIOMETER}

Since the amplifiers always drift with time and have a noise level as high as or higher than the sensitivity re-

${ }^{3}$ Nier, Ney, and Inghram, Rev. Sci. Inst. 18, 294 (1947).

$\begin{array}{ll}4 \mathrm{R} 14 & 1000 \text { ohms, } 50 \text { watt } \\ 4 \mathrm{R} 15 & 25,000 \text { ohms, precision wire wound } \\ 4 \mathrm{R} 16 & 80 \text { ohms, special wire wound } \\ 4 \mathrm{R} 17 & 40 \text { ohms, special wire wound } \\ 4 \mathrm{R} 18 & 12 \text { steps of } 26 \text { ohms each special wire wound } \\ 4 \mathrm{~V} 1 & \text { VX-41A obtained from Victoreen Instrument Company, } \\ 4 \mathrm{~V} 2 & \text { Cleveland, Ohio } \\ 4 \mathrm{V3} & 12 \mathrm{SL}, 7-\mathrm{GT} \\ 4 \mathrm{V4} & 12 \mathrm{SL}, 7-\mathrm{GT} \\ 4 \mathrm{C} 1 & 12 \mathrm{~J}-\mathrm{GT} \\ 4 \mathrm{C} 2 & 100 \mathrm{micro}-\mathrm{microfarad} \text { variable air dielectric condenser } \\ & 0.002 \mathrm{mfd} \text { condenser } 400 \mathrm{v}\end{array}$

quired, it is necessary to have a record of the state of balance of the potentials produced by the two peaks being compared, and it is necessary to be able to change from one sample to another very rapidly.

Two complete feed systems with gas volumes, mercury leveling reservoirs, and capillary leaks of the type previously described by Nier were attached to the mass spectrometer through a magnetically operated valve which delivered one sample to the mass spectrometer and the other to a waste vacuum line. In this way the flow of the two samples could be reversed rapidly. Since the valve is on the high vacuum side of the leaks there is a very small lag in changing from one sample to the other. The tube leading from the valve to the mass spectrometer must be fairly large in order that the hold up in this region is small. In our instrument the volume of the valve and connecting tube is about $10 \mathrm{cc}$ and the internal diameter and length of the feed tube within the mass spectrometer head are $3 \mathrm{~mm}$ and $12 \mathrm{~cm}$, respectively. The greater resistance of a $2-\mathrm{mm}$ I.D. tube considerably increased the time lag. The gases replace each other in a few seconds. The construction of the valve is shown in Fig. 6. The memory effect of each gas is small and hence when samples of nearly identical composition (differing by, say, 5 permil in the ratio) are compared, this effect is insignificant. However, if samples of substantially different isotopic composition are used, say differing by a few percent in the ratio, then some minutes must elapse before steady conditions are established. If carbon dioxide containing oxygen of double the normal concentration or higher is used, the 


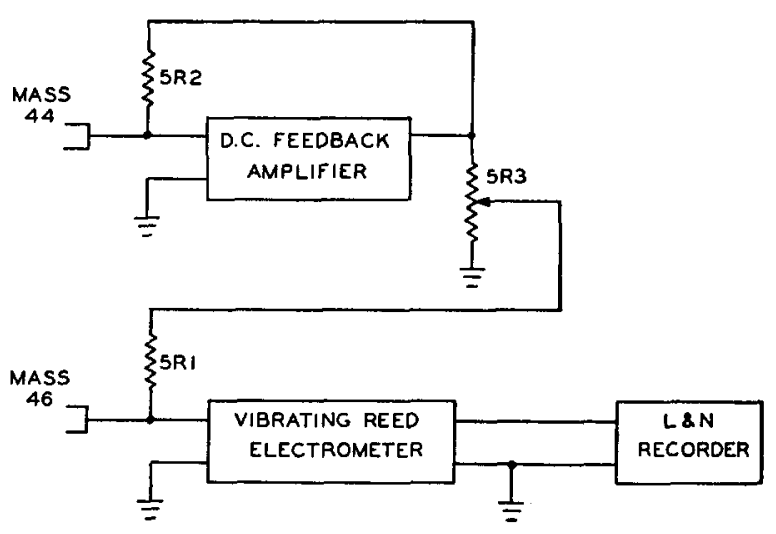

FIG. 5. Parts list for ion beam balancing circuit. 5R1-1.5 $\times 10^{11}$ ohms, Victoreen Hi-Megohm resistor. $5 \mathrm{R} 2-1.5 \times 10^{10}$ ohms, Victoreen Hi-Megohm resistor. 5R3-Put and take decade resistance potentiometer, made up of General Radio decade resistance units $510 \mathrm{~A}, 510 \mathrm{~B}, 510 \mathrm{C}, 510 \mathrm{D}$ and $510 \mathrm{E}$. Vibrating reed electrometer-obtained from The Applied Physics Corporation, 30 West Green Street, Pasadena, California. D. c. feedback amplifier-as shown in Fig. 4.

feed system that contained the concentrated gas will contaminate succeeding samples so that analysis to high precision, i.e., differences of the order of 0.2 permil in the ratio, cannot be made until the apparatus has been pumped and swept out for many days.

It is not possible to judge the steadiness of the balance of the two potentials by watching a galvanometer when it is desired to detect differences of the order of the unsteadiness of the potentials being observed. The galvanometer fluctuates unsteadily, and whether the mean has any reliable meaning cannot be judged. The recording potentiometer makes a trace which can be averaged over a satisfactory period of time.

We have used recording potentiometers to observe the balance between the potentials of the two peaks. The recorder draws an irregular line down the chart with negligible drift (if the instrument is in proper adjustment). If erratic fluctuations occur the instrument is unreliable. Of course, if the small but statistically regular fluctuations are too great the precision desired cannot be secured. By observing the record for some time it is possible to judge the stability of the amplifier circuits particularly as well as the mass spectrometer as a whole, and thus decide whether analyses can be made.

FIG. 6. Valve for reversing samples. 1 , inlet for sample $1 ; 2$, inlet for sample $2 ; 3$, outlet to waste vacuum; 4 , outlet to mass spectrometer; 5 , coil windings; 6 , soft iron washer on glass valve.

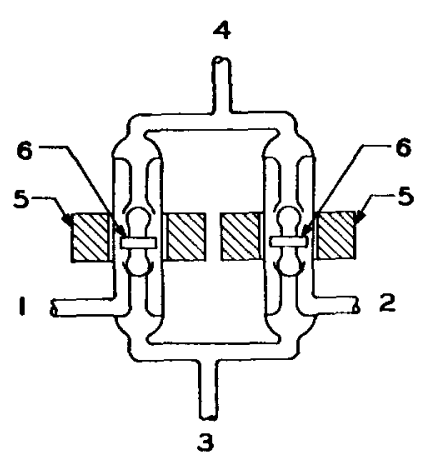

FIg. 7. Sample potentiometer record.

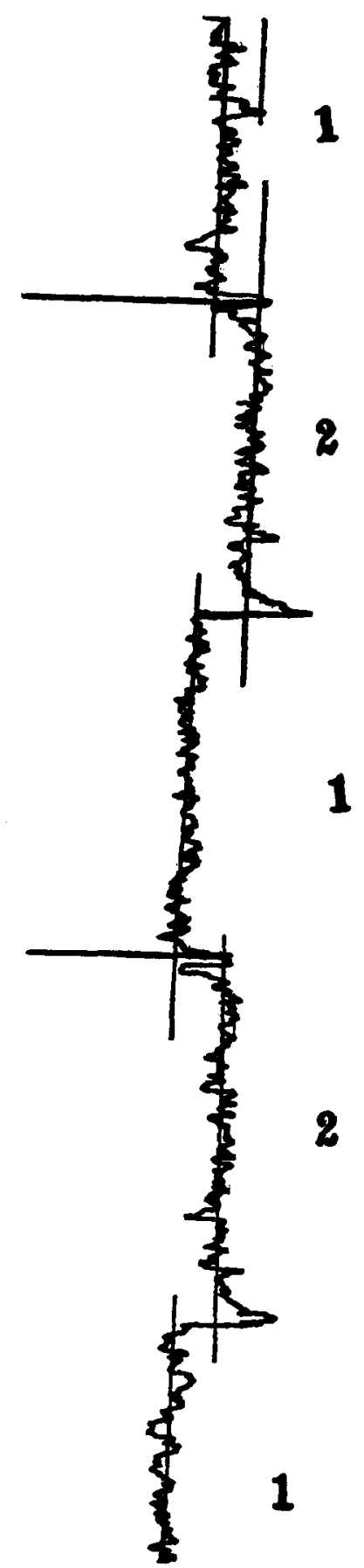

The use of the recording potentiometers is essential to securing differences to a precision of 0.2 permil of the oxygen isotope ratio.

The type of traces obtained are shown in Fig. 7, where trace 2 represents the null point of the standard and trace 1 represents the deviation from the null point by an increase of 0.63 permil in the intensity of ion beam of mass 46. If the deviation from the null point was large, part of the increase or decrease in mass 46 was taken up by changing the setting on the decade resistor system. Straight lines are drawn through the irregular 
TABLE I.

\begin{tabular}{|c|c|c|c|c|c|c|c|}
\hline \multicolumn{3}{|c|}{$\mathrm{CO}_{2}$ gas } & \multicolumn{2}{|c|}{$\mathrm{CO}_{2}$ gas } & \multicolumn{3}{|c|}{$\mathrm{O}_{2} \mathrm{gas}$} \\
\hline Sample & $\delta\left(\mathrm{O}^{18}\right)$ & Date & $\delta\left(\mathrm{C}^{13}\right)$ & Date & Sample & $\delta\left(\mathrm{O}^{18}\right)$ & Date \\
\hline 1 & $\begin{array}{l}-0.53 \\
-0.59\end{array}$ & $\begin{array}{l}12 / 13 / 49 \\
1 / 4 / 50\end{array}$ & $\begin{array}{l}0.42 \\
0.50\end{array}$ & $\begin{array}{l}12 / 13 / 49 \\
1 / 4 / 50\end{array}$ & 1 & $\begin{array}{l}17.11 \\
16.77\end{array}$ & $\begin{array}{l}12 / 7 / 49 \\
12 / 8 / 49\end{array}$ \\
\hline 2 & $\begin{array}{l}-2.98 \\
-2.99 \\
-3.00\end{array}$ & $\begin{array}{l}12 / 20 / 49 \\
1 / 3 / 50 \\
1 / 3 / 50\end{array}$ & $\begin{array}{l}1.95 \\
1.75 \\
1.58\end{array}$ & $\begin{array}{l}12 / 20 / 49 \\
1 / 3 / 50 \\
1 / 3 / 50\end{array}$ & 2 & $\begin{array}{r}0.23 \\
-0.10\end{array}$ & $\begin{array}{l}2 / 10 / 50 \\
2 / 13 / 50\end{array}$ \\
\hline 3 & $\begin{array}{l}-3.87 \\
-3.83\end{array}$ & $\begin{array}{l}12 / 12 / 49 \\
1 / 3 / 50\end{array}$ & $\begin{array}{l}1.30 \\
1.35\end{array}$ & $\begin{array}{l}12 / 12 / 49 \\
1 / 3 / 50\end{array}$ & 3 & $\begin{array}{r}0.00 \\
0.00 \\
-0.20\end{array}$ & $\begin{array}{l}2 / 10 / 50 \\
2 / 11 / 50 \\
2 / 13 / 50\end{array}$ \\
\hline 4 & $\begin{array}{l}-2.30 \\
-2.56\end{array}$ & $\begin{array}{l}12 / 13 / 49 \\
1 / 4 / 50\end{array}$ & $\begin{array}{l}2.30 \\
2.46\end{array}$ & $\begin{array}{l}12 / 13 / 49 \\
1 / 4 / 50\end{array}$ & 4 & $\begin{array}{r}0.44 \\
-0.02 \\
-0.14\end{array}$ & $\begin{array}{l}2 / 10 / 50 \\
2 / 11 / 50 \\
2 / 13 / 50\end{array}$ \\
\hline 5 & $\begin{array}{l}-2.18 \\
-2.22\end{array}$ & $\begin{array}{l}12 / 22 / 49 \\
1 / 4 / 50\end{array}$ & $\begin{array}{l}1.73 \\
1.90\end{array}$ & $\begin{array}{l}12 / 22 / 49 \\
1 / 4 / 50\end{array}$ & & & \\
\hline
\end{tabular}

curves and extended to the point where the samples were changed and the differences are read at these points. The displacement on the chart is easily calibrated in terms of the dial settings in the resistance panel. The average of some five or seven readings is then used to correct the ratio read from the resistances.

\section{CONCLUSION}

Two instruments of this type have been constructed and operated, one for 18 months, the other for 6 months. At present electronics technicians can keep the instruments in operation from 50 to 75 percent of the time. The analyses are made by laboratory technicians. Altogether some two thousand high precision comparisons of oxygen isotopic abundances in carbon dioxide, some hundreds of carbon abundances in the same gas, and perhaps a hundred comparisons of oxygen isotopes in oxygen gas have been made with these instruments. Examples of check analyses are given in Table I. The recorded figures are the differences in permils of the normal ratios between the sample and the standard working gas, i.e.,

$$
\delta=\left(\frac{R_{\text {sample }}}{R_{\text {standard }}}-1\right) 1000
$$

where $R_{\text {sample }}$ and $R_{\text {standard }}$ are the ratios of $\mathrm{CO}^{16} \mathrm{O}^{18}$ to $\mathrm{CO}_{2}{ }^{16}$ for the unknown sample and reference gas respectively. These examples of analysis on carbon dioxide are taken from our working notebooks and are a group of consecutive duplicate analyses selected at random and with no omission of any results. These duplicate analyses are on different preparations of the gas from the same samples of calcium carbonate and hence the fluctuations include any variations due to the chemical preparation of the gas. (The calcium carbonate is heated to $475^{\circ} \mathrm{C}$ for 15 minutes in a stream of pure helium gas and the carbon dioxide liberated by reaction of the carbonate with 100 percent orthophosphoric acid.) Thus the operation of the instrument is at least as reproducible as indicated by these results. On the basis of analyses made before the vibrating reed amplifier was adapted to the instrument, we believe that variations greater than 0.2 permil are due to variations introduced by the method of preparing the gas, a subject which will be discussed elsewhere.

The first example of the oxygen gas analyses is for two preparations from a silicate rock. The last three examples are all for tank oxygen. The most recent of our analyses are given here since they represent the precision we have been able to attain in our most recent work. It is expected that this precision will be maintained and in fact improved in the future as we acquire more experience in these analyses. 